\title{
The role of SEM in the diagnosis of expansive chemical reactions in cement- based building materials
}

\author{
A. Santos Silva*, M. Manuela Salta*, P. Menezes*, S. Couto* and P. Adriano* \\ * Materials Department, National Laboratory of Civil Engineering, Av. Brasil 101, 1700-066 \\ Lisbon,Portugal, ssilva@lnec.pt,msalta@lnec.pt, apmenezes@lnec.pt, scouto@lnec.pt, \\ padriano@lnec.pt
}

The alkali-silica reaction (ASR) and internal sulfatic reaction (ISR), normally both referred as internal expansive reactions, are among the most common causes of concrete structures deterioration worldwide. These reactions, which could be present simultaneously, origin products those are responsible for expansive stresses in the cement-based building materials, leading to severe cracking and loss of strength. The reaction products are also often amorphous or badly crystallized, or even present in very low content that they are very difficult to identify by current analytical physico-chemical techniques. The main macroscopic evidence of these degradation phenomena in concrete structures are the superficial occurrence of map-cracking, pop-outs and exudates (figure 1). Nevertheless, these symptoms are not exclusive and enough to establish a correct diagnosis [1].

The observation of the cement-based materials microstructure by scanning electron microscopy coupled with x-ray microanalysis (SEM-EDS) appears as an important tool, not only for detection but also for the knowledge about its dissemination inside the material, being the only technique capable of distinguish unequivocally ASR (figure 2a) from ISR (figure 2b). This work presents the results of the application of SEM-EDS in the diagnosis of deterioration cause of a concrete bridge.

The concrete samples were drilled in two zones, selected with respect to the different superficial occurrence of map-cracking. The samples were examined visually and by stereo-optical microscopy for detection of signs of deposits. Concrete zones with high humidity around the aggregates or with white deposits in the voids were further selected for analysis by SEM/EDS.

SEM observations were performed on a scanning electron microscope (SEM) JEOL JSM-6400 coupled with an OXFORD EDS detector, both on polished surfaces (with backscattered electrons - BSE images) and freshly fracturated surfaces (using secondary electrons - SEI images) that were sputtered with carbon in a JEOL JEE-4X vacuum evaporator [2].

The SEM/EDS study showed the existence of ASR products (gels and semi-crystallized forms) figure $3 \mathrm{a}, \mathrm{b}$ - in concrete, even in the non-cracked zones. Besides the ASR products detected, large amounts of ettringite were observed, only in the cracked concrete zones. The morphological features of the ettringite detected (figure 3c), mainly in compressed or compact forms, was attributed to ISR caused by cement type, concrete mix design and curing temperature. The observation of ISR and ASR prompted an investigation on the residual reactivity of the concrete to alkalis and sulphates to prognose the long-term behaviour of the deteriorated bridge structure.

The obtained results clearly show the advantage of SEM observation in the identification of the concrete bridge degradation causes. 
References:

[1] A. Santos Silva, PhD Thesis (in Portuguese), Minho University, Guimarães, Portugal (2005).

[2] P.E. Stutzman, J.R. Clifton, Proceedings of the $21^{\text {st }}$ ICCM (1999) 10-22.

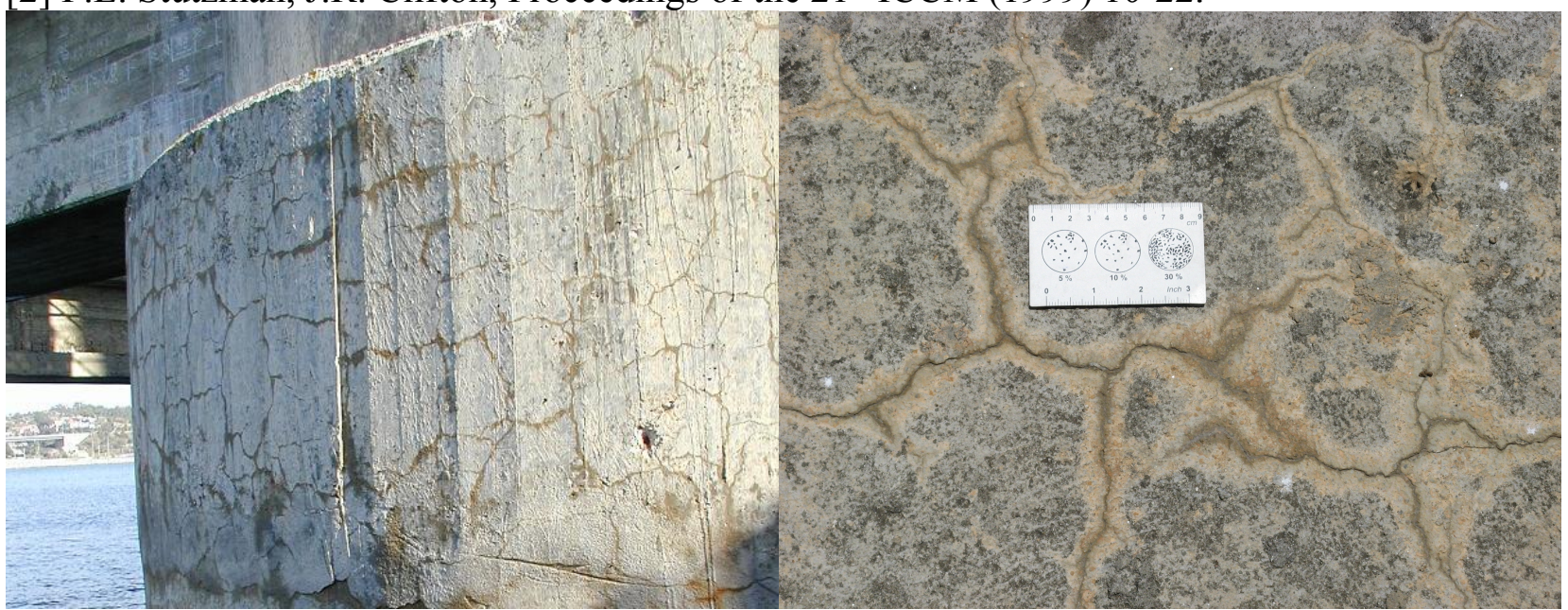

Figure 1. Typical visual symptoms of internal expansive reactions affecting concrete structures.

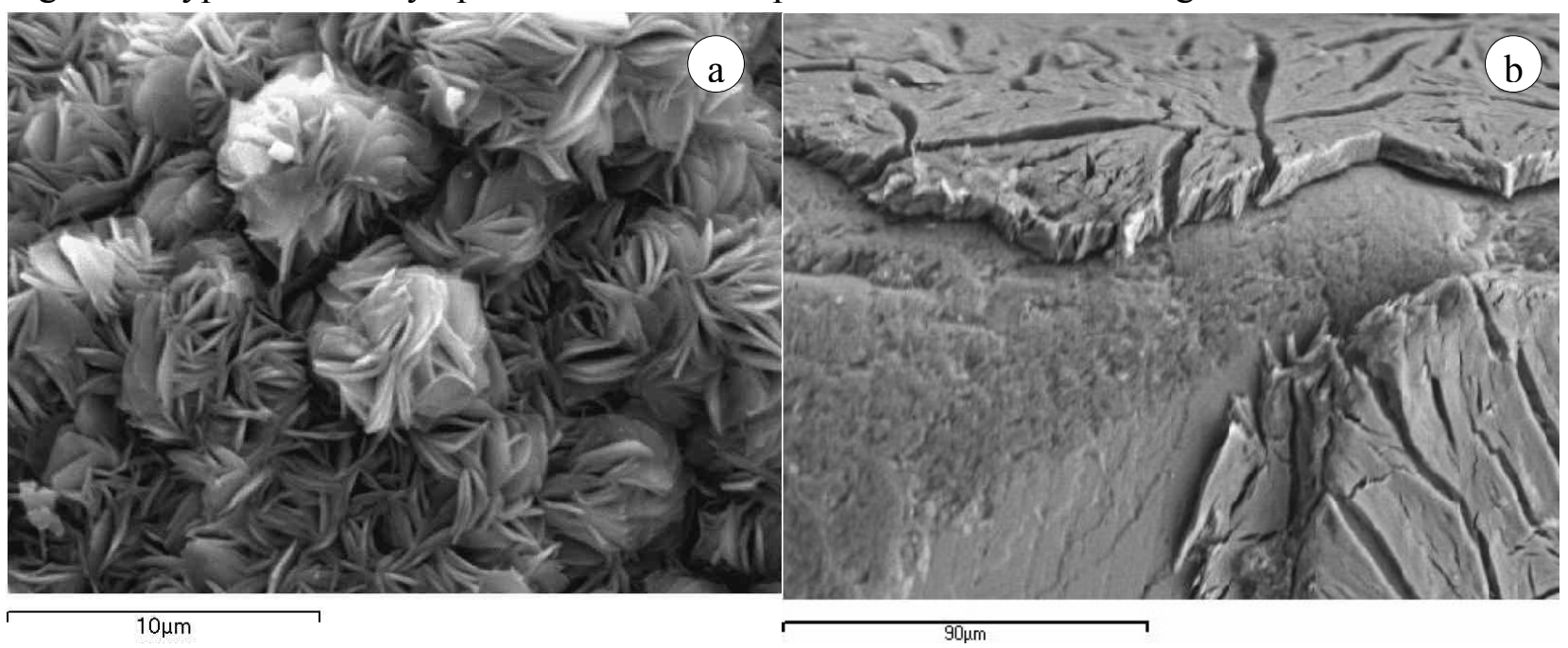

Figure 2. SEM images of (a) ASR semi crystalline product and (b) compressed ettringite (ISR product) in cement paste/aggregate interfaces in concrete.

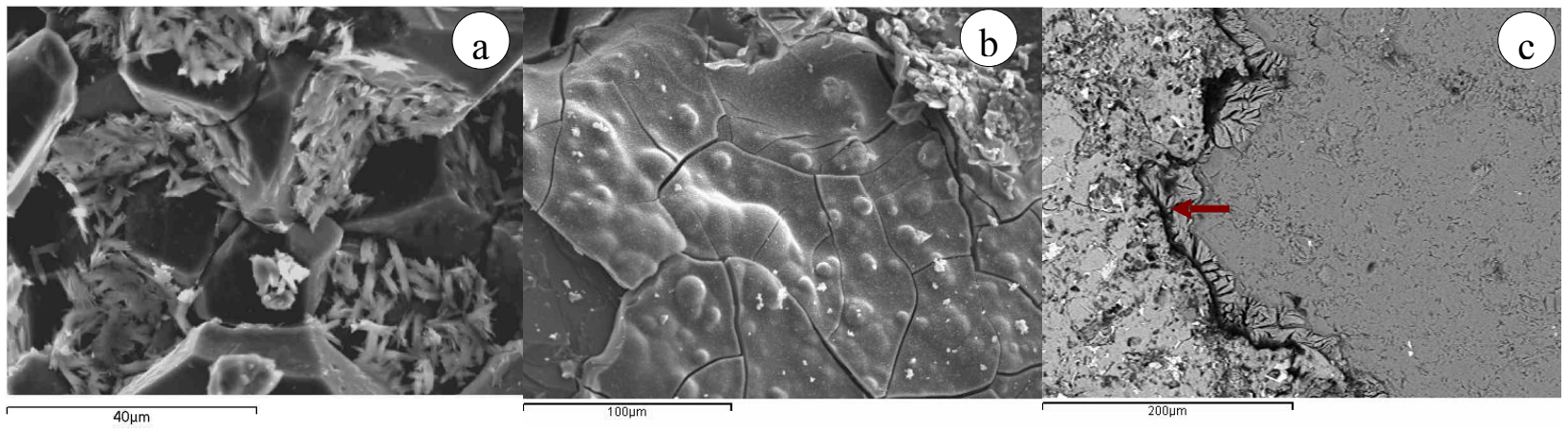

Figure 3. SEI images showing various forms of ASR products: (a) lamellar ASR crystals in a quartzite grain, (b) concomitance of bump-shaped gel and botryoïdal ASR products, (c) BSE image of compressed ettringite around an aggregate particle. 